\title{
AVALIAÇÃO DA FRAGILIDADE GEOSSISTÊMICA DE UMA MICROBACIA SOBRE GEOLOGIA CÁRSTICA: POTENCIAL E LIMITAÇÕES ${ }^{1}$ \\ Geosystemic fragility assesment of a carstica geological bassin: potential and limitations
}

\author{
Nicolas FLORIANI ${ }^{2}$ \\ Celina WINIEWSKI ${ }^{3}$ \\ Naldy E. CANALI ${ }^{4}$ \\ Dimas FLORIAN ${ }^{5}$ \\ Andréa Mayer VEIGA ${ }^{6}$
}

\section{RESUMO}

Incorporando o Suporte à Decisão por Múltiplos Critérios à lógica fuzzy para a modelagem dos dados ambientais, construiu-se uma alternativa ao mapeamento da fragilidade ambiental proposta por Ross (1994) da bacia hidrográfica cárstica estudada. Na primeira etapa metodológica buscouse aplicar critérios diferentes para superar a rigidez da classificação dos solos. Na segunda etapa, adotou-se a ferramenta Analytical Hierarchy Process associada à lógica fuzzy para determinar diferenças entre os elementos solo, declividade, geologia e geomorfologia, com maior peso para o solo. Constatou-se que a metodologia alternativa proposta apresentou resultados diferentes aos de Ross (1994), uma vez que baseou seus pressupostos no debate teórico da sustentabilidade.

\section{Palavras-chave:}

Fragilidade ambiental; geossistemas; paisagem e solos; lógica fuzzy.

\begin{abstract}
The incorporation of the Multicriteria Decision-Making methodology from fuzzy logic to the environmental data model has allowed an arrangement mapping of environmental fragility (Ross, 1994) from the studies of the hydrographic carstica bassin. At the first step of methodology were applyied different criteria to overcome the strict classification of soils. In the second step, the Analytical Hierarchy Process wich uses fuzzy logic allowed to determine differences among the soil, slope, geology and geomorfology, with major value ascribed to the soil. This way, it's possible to remark that the purposes of alternative methodology presented a very different output from those of Ross (1994), as the last one based his presuppositions on sustainability theoretical debate.
\end{abstract}

\section{Key-words:}

Environmental fragility; geossystems; landscape and soils; fuzzy logic.

\footnotetext{
${ }^{1}$ Parte da Dissertação de Mestrado em Ciências do Solo da UFPR, do primeiro autor.

${ }^{2}$ Doutorando em Meio Ambiente e Desenvolvimento da UFPR. e-mail: nicolas@casla.com.br.

${ }^{3}$ Professora do Dep. de Solos/UFPR. e-mail: cewisni@agrarias.ufpr.br.

${ }^{4}$ Professor do Dep. de Geografia da UFPR. e-mail: canali@qwnet.com.br.

${ }^{5}$ Professor do Dep. de Ciências Sociais da UFPR, e-mail: floriani@ufpr.br.

${ }^{6}$ Doutoranda em Produção Vegetal da UFPR. e -mail: andrea@casla.com.br.
} 


\section{INTRODUÇÃO}

Localizada no Município de Colombo, parte integrante da Região Metropolitana de Curitiba, Estado do Paraná, a Bacia Hidrográfica de Fervida e Ribeirão das Onças apresenta, atualmente, um quadro de crise que confere riscos para a sustentabilidade do ecossistema: a exploração dos recursos hídricos subterrâneos (aqüífero cárstico) por meio do bombeamento de poços artesianos para atender às demandas dos grandes centros urbanos; o uso da água de superfície para a irrigação de produtos hortigranjeiros; a produção de hortaliças de forma convencional, sobre áreas de interesse de proteção ambiental; os sistemas agrícolas predominantemente intensivos, e os jogos de interesses entre estilos de vida opostos (urbano x rural).

Frente àquelas situações de conflito, peculiares às sociedades de risco, nas quais a produção dos riscos ecológicos tem origem inevitavelmente no centro do próprio processo de produção de riquezas, justifica-se a necessidade de se pensar formas alternativas ao desenvolvimento rural, ou seja, torna-se crucial repensar uma forma de desenvolvimento que satisfaça as necessidades de reprodução social e econômica de cada comunidade e estabelecimento rural, bem como a manutenção, em longo prazo, dos recursos naturais e da produtividade agrícola com um mínimo de impactos adversos aos sistemas ambientais.

Neste caso, justifica-se o planejamento do uso sustentável das terras através da aplicação de metodologias que identifiquem e mapeiem a fragilidade e a vulnerabilidade geossistêmica a fim de propiciar formas de planejamento do uso correto dos solos, o manejo e o gerenciamento da paisagem com seus recursos naturais.

O estudo dos sistemas ambientais ou dos geossistemas surge a partir da construção de uma nova análise da paisagem, buscando o entendimento da sua estrutura e dinâmica, ou seja, na busca da compreensão do complexo da paisagem. A compreensão deste complexo passa, de um lado, pelo entendimento da lógica de apropriação da natureza e das tecnologias utilizadas para tal e, por outro, pelo entendimento do jogo triangular das interações dinâmicas entre biocenose-pedogênesemorfogênese, que está no centro das influências do clima sobre o relevo e cuja somatória das forças resulta na estabilidade ou na instabilidade da superfície (BERTRAND, 1971; SOTCHAVA, 1978).

O conhecimento da dinâmica desses processos, a partir da metodologia da Ecodinâmica (TRICART, 1977) - que tem como foco principal a análise dos processos morfogênicos que produzem a (e)instabilidade da superfície - torna-se o elemento determinante para a adminis- tração e ordenamento do ambiente, lembrando que um dos seus objetivos é a diminuição da instabilidade morfodinâmica dos meios.

Assim, com base no estudo geossistêmico associado à metodologia da ecodinâmica, é possível responder aos objetivos estipulados no estudo que são: analisar os graus de fragilidade natural do relevo, mapeandoos, bem como analisar a fragilidade da superfície face às intervenções antrópicas.

Não obstante, as metodologias baseadas nas ciências tradicionais mostram-se incapazes de analisar os sistemas ambientais complexos caracterizados pela subjetividade e imprecisão. Na modelagem dos sistemas ambientais e no manejo de conflitos advindos da escolha de múltiplos critérios para a resolução dos problemas socioecológicos, deve-se dar preferência a ferramentas que considerem as incertezas e a pluralidade de perspectivas.

As ferramentas capazes de incorporar múltiplos critérios para a formação de assuntos ambientais podem ser utilizadas na análise da fragilidade ambiental à medida que os elementos do geossistema variam ou mudam de valor, de acordo com o momento histórico ou com o lugar em que se encontram. Os métodos de avaliação de múltiplos critérios são, em princípio, uma apropriada ferramenta de modelagem para a formação de decisões em assuntos ambientais, pois se encarregam de tratar de informações do tipo mesclado (medidas qualitativas e quantitativas) quando incorporam o quadro da incerteza estocástica, chamada de "incerteza fuzzy" que enfoca a ambigüidade da informação (FUNTOWICZ et al., 1999).

Assim, face aos objetivos do trabalho, deu-se maior importância ao fator solo na análise da fragilidade ambiental, dada sua importância como fator de estabilização dos processos morfodinâmicos na paisagem (CHORLEY, 1971; CHRISTOFOLETTI, 1974; GERRARD, 1992; RUELLAN; DOSSO, 1993; CASSETI, 1991, 2001), como fator de produtividade dos agroecossistemas (IGUE, 1983; PRIMAVESI, 1983; KIEHL,1985), e como fator de contaminação ou depuração das águas superficiais e subterrâneas (TRICART, 1977; FOSTER, 1988; TEODOROVICZ et al, 1994; EMATER, 1997; ROBERT, 1996; FRITSZONS, 1999), características estas do ambiente cárstico no qual se aplicou o estudo.

\section{MATERIAL E MÉTODOS}

\section{DETERMINAÇÃO DAFRAGILIDADE AMBIENTAL}

A análise empírica da fragilidade ambiental da Bacia Hidrográfica de Fervida e Ribeirão das Onças (BHC-FR) está baseada na metodologia de mapeamento da fragili- 
FIGURA 1 - FLUXOGRAMA DAS ATIVIDADES E PRODUTOS SOBRE A FRAGILIDADE AMBIENTAL

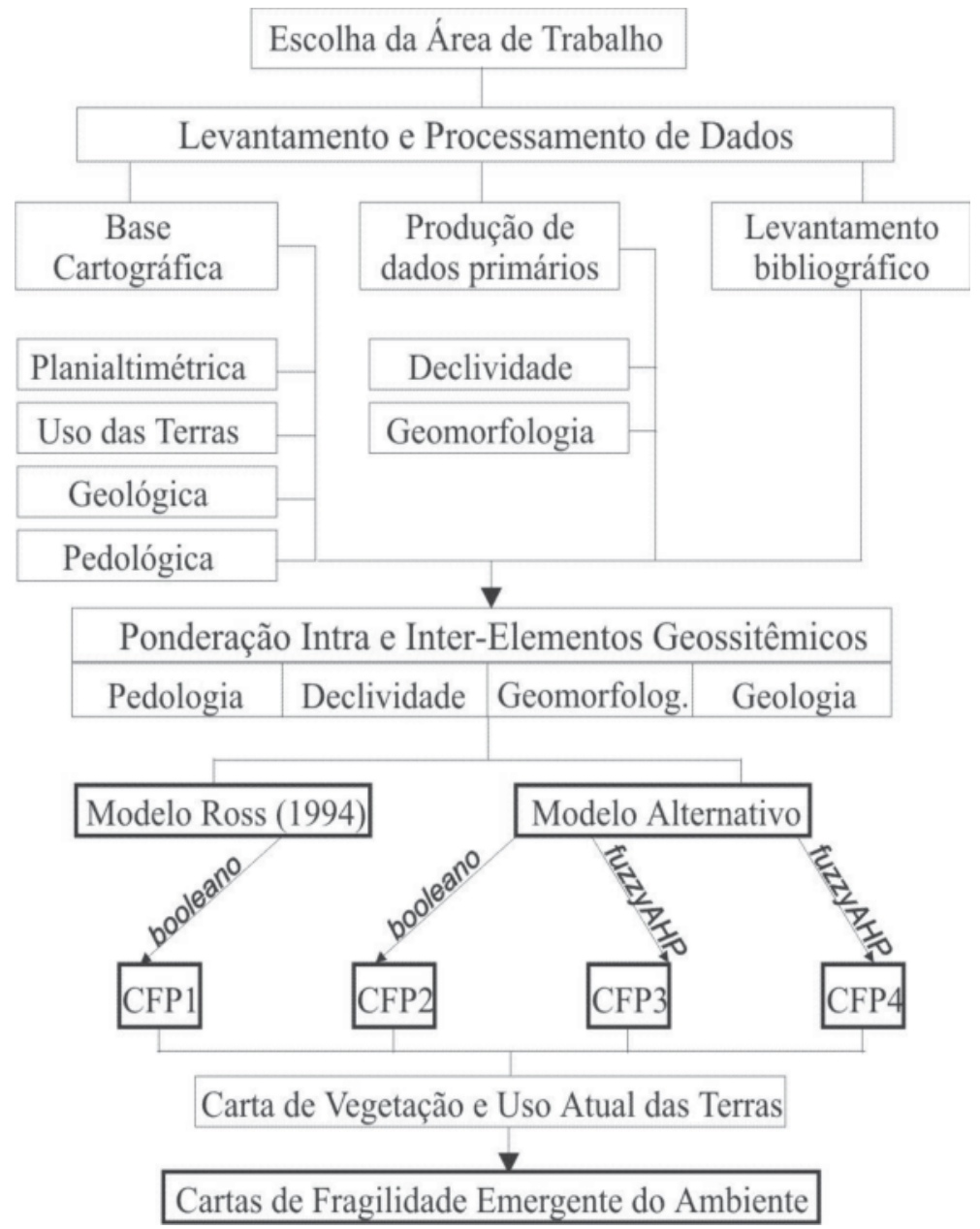

dade ambiental de Ross (1994), cujo organograma encontra-se na Figura 1.

O mapeamento foi realizado, preferencialmente, em meio digital, onde foram usados, como base, os mapas temáticos já existentes ${ }^{7}$, desde que em escala compatível. Os mapas temáticos foram digitalizados em sistema de informações geográficas utilizando-se o software SPRING 3.6.03 (INPE, 2003), uma ferramenta desenvolvida pelo Instituto Nacional de Pesquisas Espaciais desde 1991. Escolheu-se para representação cartográfica a escala de 1:10.000, sendo executados nesta escala os mapeamentos primários realizados na área de pesquisa.

A primeira etapa da metodologia consistiu no levantamento da base cartográfica (mapas de planialtimetria, pedologia, geologia e uso da terra); na produção de dados primários (mapas de declividade e geomorfologia) e referências bibliográficas.

A segunda etapa metodológica consistiu na correlação de todas as informações acima geradas. Para tanto, efetuou-se um sistema de ponderação para cada elemento geossistêmico (pedologia, geomorfologia e geologia). Da correlação dessas informações pode-se construir uma matriz na qual foram identificadas as unidades de paisagem, juntamente com os seus componentes físicos e biológicos que estruturam o geossistema em

7 A Base Cartográfica existente consiste nos mapas de Pedologia (EMATER, 1997), na escala de 1:10.000, de Geologia (MINEROPAR, 1997), na escala 1:20.000, de Planialtimétria (COMEC, 1976), na escala 1:10.000 e Uso das Terras, na escala 1:10.000, a partir da classificação supervisionada das Imagens Landsat 5 de 2001. 
FIGURA 2 - IMAGEM SOMBREADA DO RELEVO DA BHC-FR E UNIDADES DE PAISA-
GEM

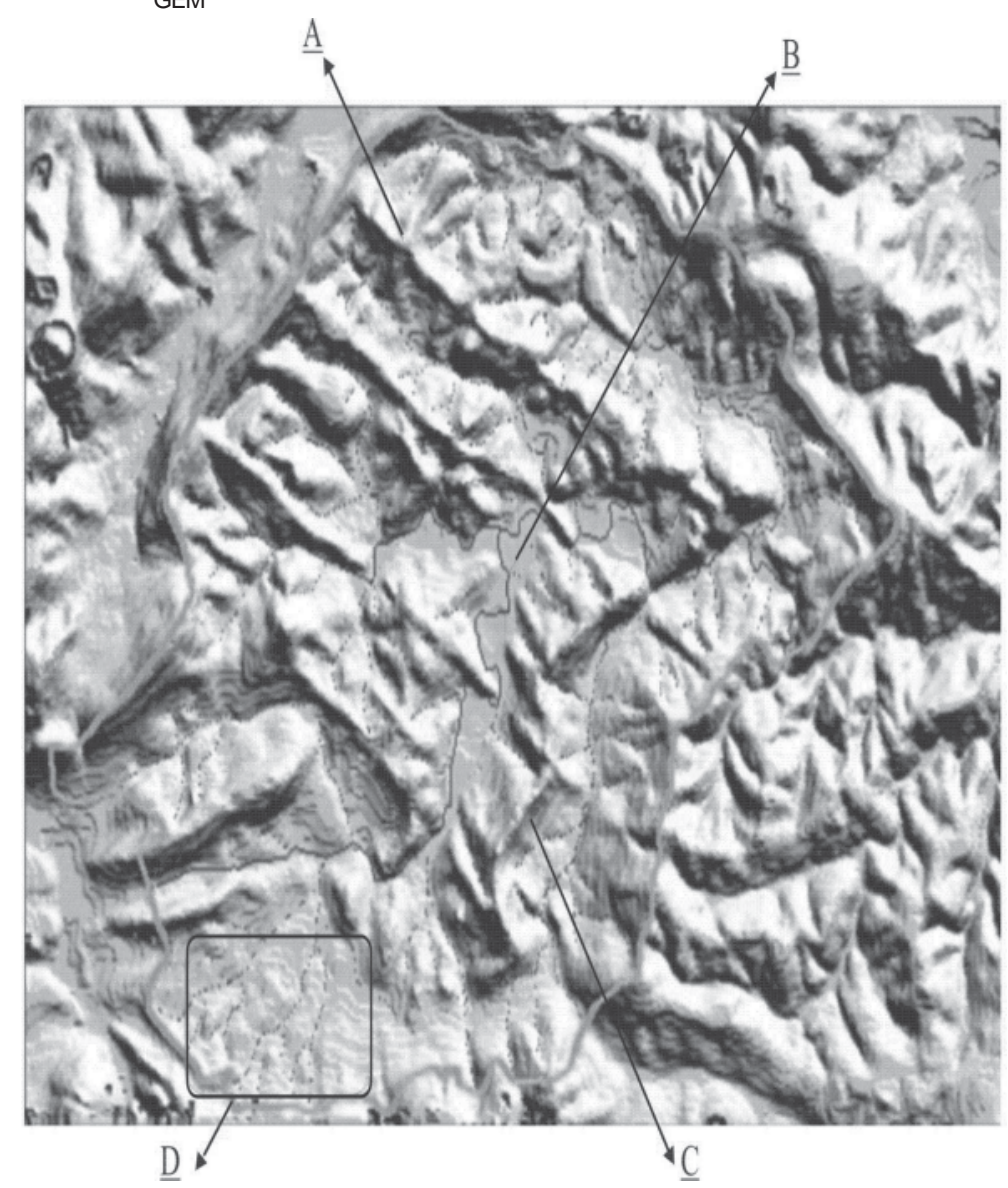

questão. Para efeito de interpretação, essas unidades de paisagem foram distribuídas de forma esquemática na imagem sombreada do relevo gerada durante o estudo que pode ser visualizado na Figura 2.

Na Unidade de Paisagem (UP) A, os terrenos são constituídos principalmente pelos Diques de diabásio, relacionados ao magmatismo Mesozóico, configurado por morros médios a altos, estreitos, bastante alongados na direção NW-SE, com encostas convexo-retilíneas curtas, com declividades variando de moderada (20 a 39\%) a alta (>30\%). Nestes ambientes, estão desenvolvidos os NITOSSOLOS VERMELHOS Eutroférricos típicos.

Na UP B, ocorrem planícies aluviais muito estreitas, a exemplo dos aluviões do rio Capivari ; não apresenta encostas, sendo o relevo plano. O desnível altimétrico é muito baixo ou praticamente nulo, a declividade média é de 0 a 5\%. Nesta UP, estão assentadas geologia do Terciário-Quaternário (aluviões atuais), desenvolvendose neste ambiente os GLEISSOLOS MELÂNICOS.

Na UP C, ocorrem terrenos constituídos de cristas Quartzíticas e Filíticas (somando cerca de 33\% das classes geológicas da bacia) do Proterozóico, de cotas variando entre 1000 a 1200m. São configurados por morros altos, estreitos, alongados no sentido SW-NE, com encostas convexo-retilíneas curtas, com declividades médias maiores que 30\%. Nesses ambientes estão desenvolvidos os CAMBISSOLOS HÁPLICOS Tb distróficos e os NEOSSOLOS LITÓLICOS Eutróficos e Distróficos. Nesta UP, devido ao relevo acidentado e à impossibilidade de acesso, as Florestas permanecem em estagia de sucessão secundária $(28,21 \%$ do total das classes de uso das terras), juntamente com o cultivo de Bracatinga (Mimosa scabrela) que perfaz $24,35 \%$ do total desta categoria. Na UP D, dominam os terrenos topograficamente rebaixados, de encostas do tipo convexas longas, de colinas e morros baixos, com declividade média entre 0$6 \%$, assentados sobre geologia dos Metadolomitos (49,79\% da área da bacia) do Grupo Açungui/Formação Capiru, onde se desenvolvem os CAMBISSOLOS HÚMICOS Alumínicos latossólicos.

A partir da identificação dos componentes geossistêmicos e da sua compartimentação em Unida- 
TABELA1- RESUMO DA PONDERAÇÃO DA FRAGILIDADE AMBIENTAL E DISPOSIÇÃO HIERÁRQUICA DOS ELEMENTOS SEGUNDO ROSS (1994)

\begin{tabular}{|c|c|c|c|c|c|}
\hline \multirow{2}{*}{\multicolumn{2}{|c|}{ Classes de fragilidade }} & \multicolumn{4}{|c|}{ Elementos do Geossistema } \\
\hline & & Pedologia & Declividade & Geomorfologia & Geologia \\
\hline \multirow{5}{*}{ Peso } & (Muito Baixa) & -- & $\mathrm{P}$ & -- & Qua \\
\hline & (Baixa) & -- & S.O. & -- & Pel \\
\hline & (Média) & TBRE & 0 & $\mathrm{R} 2$ & Diq \\
\hline & (Alta) & $\mathrm{Cd} \mathrm{e} \mathrm{Ca}$ & F.O. & R3 & Dol \\
\hline & (Muito Alta) & $\mathrm{R}$ e Hg & $\mathrm{M}$ & R1 & Alu \\
\hline
\end{tabular}

TBRE = TERRA BRUNA ROXA ESTRUTURADA; Ca = CAMBISSOLO LATOSSÓLICO; Cd = CAMBISSOLOS; R = LITÓLICOS; $\mathrm{Hg}=$ HIDROMÓRFICOS; $\mathrm{P}=$ PLANO; S.O.= SUAVE ONDULADO; O = ONDULADO; F.O. = FORTE ONDULADO: $M$ = MONTANHOSO; $R 1$ = PLANÍCIES ALUVIAIS $\cdot R 2$ = ENCOSTAS CONVEXAS LONGAS E CÔNCAVO-CONVEXAS CURTAS; R3 = ENCOSTAS CONVEXAS E CONVEXO-RETILÍNEAS CURTAS; QUa = QUARTZITOS; $\mathrm{Pe}=$ METAPELITOS; Diq = DIQUES DE DIABÁSIO; Dol = METADOLOMITOS; Alu = ALUVIÕES

TABELA 2 - PESOS ADOTADOS E DISPOSIÇÃO HIERÁRQUICA DOS ELEMENTOS SEGUNDO MODELO ALTERNATIVO PROPOSTO

\begin{tabular}{|c|c|c|c|c|c|}
\hline & \multicolumn{4}{|c|}{ Elementos do Geossistema } \\
\hline \multicolumn{2}{|c|}{ Classes de fragilidade } & Pedologia & Declividade & Geomorfologia & Geologia \\
\hline & (Muito Baixa) & -- & $P$ & -- & Qua \\
\hline & (Baixa) & -- & S.O. & $\mathrm{R} 2$ & Pel \\
\hline \multirow[t]{3}{*}{ Peso } & (Média) & $\mathrm{TBRE}+\mathrm{Ca}$ & $\mathrm{O}$ & R3 & Diq \\
\hline & (Alta) & $\mathrm{Cd}$ & F.O. & -- & Dol \\
\hline & (Muito Alta) & $\mathrm{R}$ e $\mathrm{Hg}$ & $\mathrm{M}$ & $\mathrm{R} 1$ & Alu \\
\hline
\end{tabular}

*NO LEVANTAMENTO DETALHADO DOS SOLOS, REALIZADO POR EMATER (1997), OS SOLOS FORAM ENQUADRADOS SEGUNDO O ANTIGO SISTEMA BRASILEIRO DE CLASSIFICAÇÃO DE SOLOS (EMBRAPA, 1984).

TABELA 3 - PESOS DEFINIDOS PELA TÉCNICA fUzZYAHP

\begin{tabular}{|c|c|}
\hline Pesos & Categorias \\
\hline 0.524 & Pedologia \\
\hline 0.271 & Declividade \\
\hline 0.135 & Geomorfologia \\
\hline 0.070 & Geologia \\
\hline
\end{tabular}

des de Paisagem, um sistema de ponderação é estruturado conforme metodologia de mapeamento da fragilidade ambiental (ROSS, 1994) e outro na metodologia alternativa proposta, podendo ambos ser conferidos nas Tabelas 1 e 2.

Na metodologia alternativa sugerida neste trabaIho, atribuíram-se pesos diferenciados para as classes (ex. classe dos relevos planos, classe dos cambissolos latossólicos, classe dos quartzitos, etc.) dentro de cada subsistema e pesos diferenciados entre os mesmos (pedologia, declividade, geomorfologia, geologia). A ponderação dos elementos pode ser conferida na Tabela 2.

Como referido, os subsistemas também receberam pesos e, nesta lógica, os solos recebem maior peso, de- pois declividade, geomorfologia e geologia. A valoração foi apoiada estatisticamente na técnica do processo analítico hierárquico - Analytical Hierarchy Process (AHP) - associada à lógica fuzzy, disponível no software SPRING 3.6.03 (INPE, 2003), podendo ser visualizada na Tabela 3. Hardy (1996) declara que na teoria dos conjuntos nebulosos "tudo é uma questão de valoração", tendo os conjuntos limites imprecisos. Nesse caso, quando grupos de valores incertos e vagos estão em jogo no processo de tomada de decisão, as técnicas da lógica fuzzy provêem ferramentas poderosas para avaliar inúmeras alternativas em um ambiente de incerteza. Permitem quantificar, deste modo, critérios vagos ou qualitativos, provendo o tomador de decisão com discernimento adicional no processo de seleção dos atributos. 
Uma das técnicas utilizadas como alternativa ao modelo booleano ${ }^{8}$ é o processo analítico hierárquico Analytical Hierarchy Process (AHP), desenvolvido pelo matemático Thomas L. Saaty e considerado como sendo o mais promissor no contexto do processo de tomada de decisão. Pelo fato de muitas variáveis de entrada (inputs) no processo de tomada de decisão não terem base estatística, outros métodos são requeridos. O método fuzzyAHP apresenta-se como uma ferramenta adequada ao processo de tomada de decisão ao analisar os conjuntos de valores e atributos subjetivos (qualitativos). Os procedimentos sistemáticos usados pela metodologia AHP de Saaty resulta em ordenar prioridades, que podem ser usadas para selecionar ou classificar alternativas (FULLER; CARLSSONN, 1996; INPE, 2003).

De maneira semelhante ao procedimento usado no módulo AHP do programa SPRING 3.6.3, Cheng e Mon, citados por Fuller e Carlsson (1996), desenvolveram números fuzzy triangulares de "1 a 9" para construir uma matriz de julgamento de comparação pareada. $\mathrm{O}$ algoritmo derivado fuzzy estima os vetores da matriz de julgamento usando um "índice I de otimismo" que indica o grau de satisfação do tomador de decisão. A técnica proposta pelos autores foi ilustrada com a seleção de melhores sistemas de artilharia antiaérea diante de um quadro de atributos qualitativos para a escolha dos armamentos.

Neste trabalho, a metodologia fuzzyAHP foi utilizada como suporte à decisão de atributos ligados à fragilidade dos elementos geossistêmicos. O procedimento consistiu em hierarquizar os elementos em uma escala de "1 a 9" com a ajuda do algoritmo fuzzy, incorporado ao módulo de suporte à decisão do sistema de informações geográficas. A hierarquização foi procedida conforme a Figura 3.

As diferenças entre as duas ponderações - a primeira de acordo com Ross (1994) e a alternativa - são resultantes da migração das categorias Ca para uma classe de fragilidade menor (3): os Cambissolos latossólicos são reavaliados pelos autores do trabalho com base na bibliografia (EMBRAPA, 1984; OLIVEIRA et al., 1992; MEDEIROS, 1994; EMBRAPA, 1999): em função das características de relevo, profundidade, estrutura, textura e capacidade de infiltração estes Cambissolos são considerados de baixa suscetibilidade erosiva e com boas possibilidades de mecanização; dentre os cambissolos da área, foi o que apresentou melhor aptidão agrícola, sendo classificado como solo de aptidão agrícola boa para todas as possibilidades de exploração, segundo os níveis de manejo $\mathrm{B}$ e $\mathrm{C}$, desde que tomadas medidas adequadas de manejo conservacionista e de fertilidade.

Assim, tais Cambissolos foram igualados às Terras Brunas Roxas estruturadas, embora pudessem ser valorados como solos de menor grau de susceptibilidade à erosão, pois não possuem as características morfológicas, como o Horizonte B textural (ou B nítico, conforme o novo Sistema Brasileiro de Classificação dos Solos) e relevo ondulado, que influenciam demais no potencial erosivo das Terras Brunas Roxas estruturadas.

As categorias geomorfológicas R2 (encostas convexas longas e côncavo-convexas curtas, em colinas e morros baixos) e R3 (encostas convexas e convexoretilíneas curtas, em morros médios a altos, estreitos, bastante alongados) também passaram para classes menores, com base em conceitos de Penteado (1974) que afirma que a massa sólida em movimento é, no perfil convexo, representada pelo rastejamento do solo e escoamento difuso, muito lento, sob efeito da gravidade, ao passo que nas encostas intermediárias retas a erosão é muito rápida - e Teodorovicz et al. (1994) que caracterizam aqueles relevos como de moderada fragilidade ao uso agrícola (desde que usadas medidas de controle da erosão) em função da boa qualidade do solo e condições topográficas relativamente favoráveis. A ponderação das classes geológicas é sugerida neste trabalho pelos autores, baseada em pesquisa bibliográfica (TEODOROVICZ et al., 1994; FIORI, 1994; LISBOA, 1997; FRITZSONS, 1999), não estando vinculada diretamente à metodologia de Ross (1994), embora adicionada na Tabela 1 (coluna Geologia).

De acordo com Foster (1988) e Teodorovicz et al. (1994), pelo fato de os definirem como zonas de cisalhamento rúptil, os diabásios apresentam o substrato rochoso extremamente fraturado e com muitas descontinuidades estruturais. Em função disto, são naturalmente muito suscetíveis a movimentos naturais de massa e também muito porosa (infiltração rápida de fluidos para o subsolo); sendo assim, a baixa vulnerabilidade é dada mais pela existência de um horizonte $B$ textural do que propriamente pelas características do diabásio; contudo, quando analisada esta característica juntamente com o uso inadequado do solo (p.ex. uso inadequado de implementos agrícolas no preparo do solo), a vulnerabilidade dessas áreas pode vir a tomar outro extremo, ou seja, em uma classe altamente vulnerável, como se verá mais adiante.

Após a ponderação dos temas cartografados procedeu-se ao cruzamento dos mesmos. Na metodologia

8 Também conhecido por Hardy (1996) como Bivalente por distribuir todas as nuances (variações) de um sistema em conjuntos de apenas dois valores: 0 (membro não-pertencente) e 1 (membro pertencente a um determinado atributo). 
FIGURA 3 - ETAPA DE HIERARQUIZAÇÃO NO MÓDULO DE SUPORTE À DECISÃO AHP DO PROGRAMA SPRING 3.6.2 (INPE, 2003)

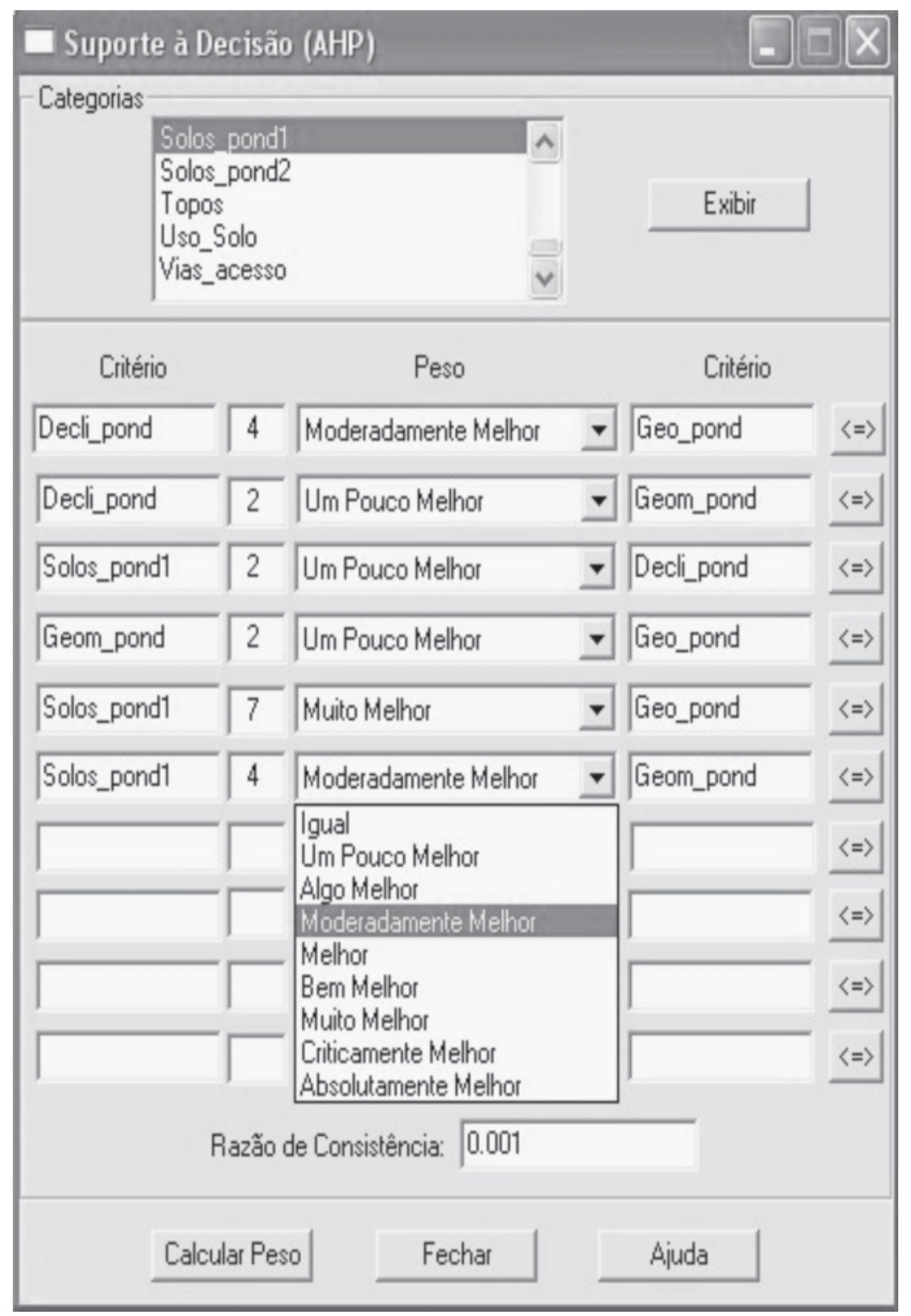

original utilizou-se a lógica booleana para o cruzamento das 04 (quatro) cartas (pedologia, declividade, geomorfologia e geologia) resultando na Carta de Fragilidade Potencial 1 (CFP1). As quatro cartas de fragilidade potencial do relevo podem ser vistas na Figura 4.

Na metodologia alternativa proposta neste estudo foram utilizadas, além da lógica booleana para o cruzamento dos temas cartografados - resultando na geração da Carta de Fragilidade Potencial 2 (CFP2) -, a lógica fuzzy Ponderado responsável pela geração das duas úl- timas cartas de fragilidade potencial (CFP3 e CFP4). A última etapa metodológica compreende o cruzamento das cartas de fragilidade potencial geradas nas etapas anteriores com a carta de uso das terras previamente ponderada, conforme os critérios sugeridos por Ross (1994). Desse cruzamento (por meio da lógica booleana) resultaram quatro (04) Cartas de Fragilidade Emergente, sínteses das fragilidades potenciais do meio natural frente aos tipos de uso das terras, caracterizando a vulnerabilidade do geossistema. 


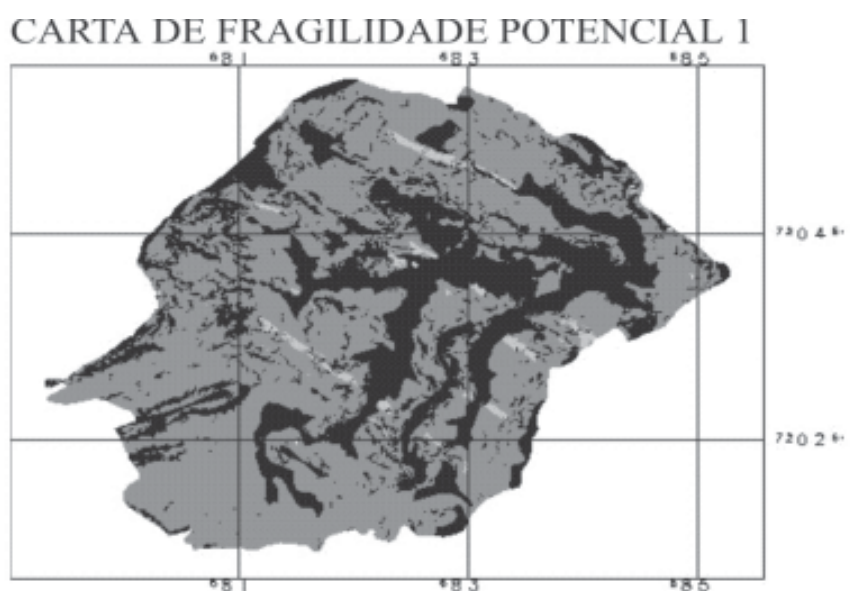

CARTA DE FRAGILIDADE POTENCIAL 3

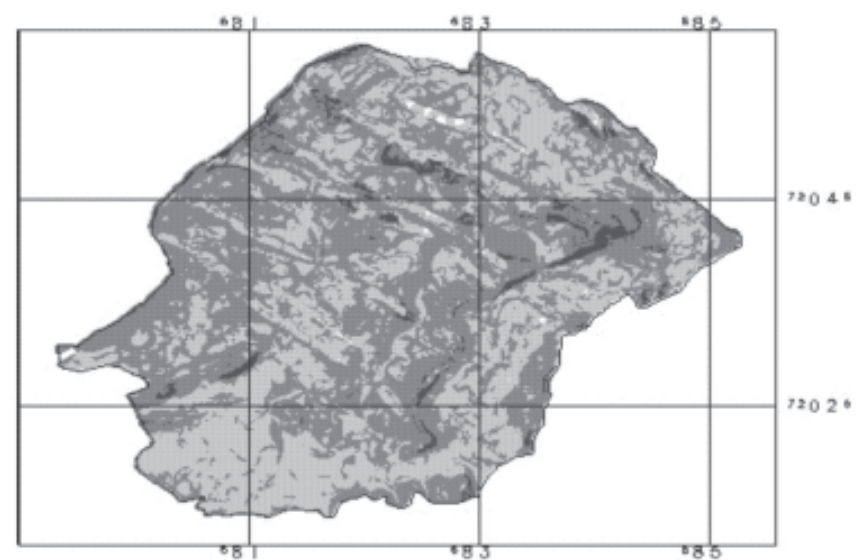

Legenda: classes de fragilidade EMuito Baixa $\square$ Média $\square$ Alta Baixa Muito Alta

\section{RESULTADOS E DISCUSSÃO}

\section{CARTAS DE FRAGILIDADE POTENCIAL DO AMBIEN- TE FÍSICO-NATURAL}

A partir da proposta de mapeamento da fragilidade do geossistema - a de Ross (1994) e a alternativa proposta neste trabalho - chegou-se a resultados que sintetizam a evolução das classes de fragilidade potencial frente aos quatro cenários (cartas) construídos no decorrer do desenvolvimento metodológico.

De acordo com esses dados, expressos na Figura 5 , conclui-se que as quatro cartas indicam valores diferenciados no mapeamento da fragilidade ambiental e, analisando-se os extremos, nota-se, na primeira coluna (CFP1), que 63,96 e 34,56\% da área da BHC-FR que se localizam, respectivamente, em classes de alta e muito
CARTA DE FRAGILIDADE POTENCIAL 2

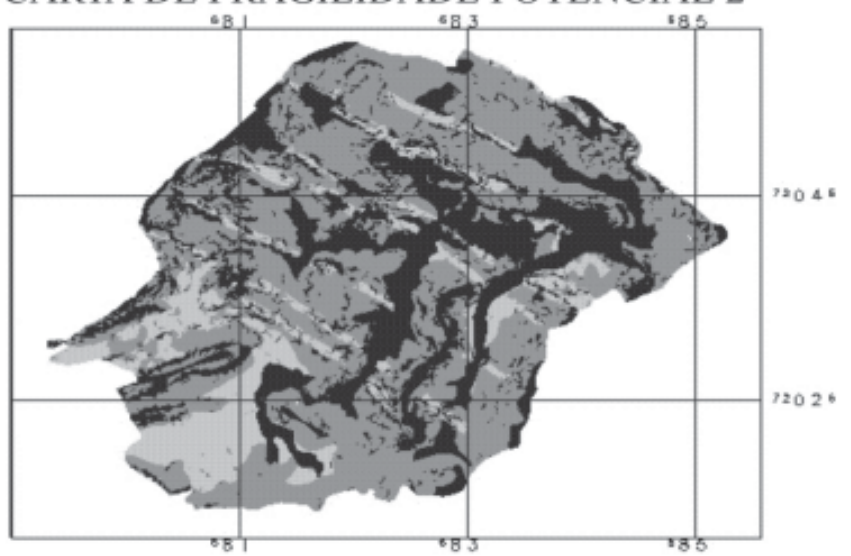

\section{CARTA DE FRAGILIDADE POTENCIAL 4}

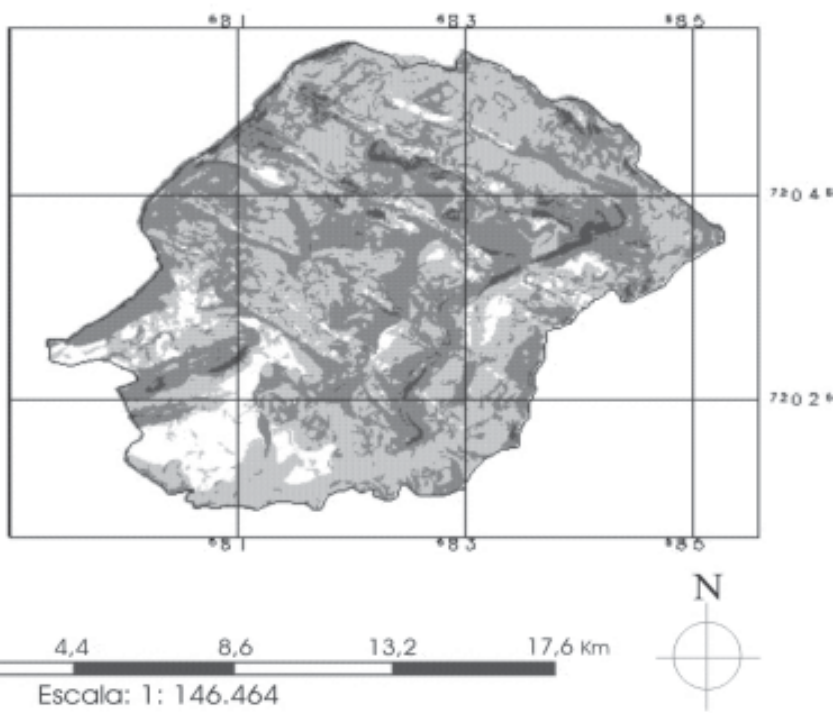

alta fragilidade potencial passam, na quarta coluna (CFP4), a ser distribuídas em classes de média $(53,70 \%)$ e baixa $(4,07 \%)$ fragilidade potencial.

Observou-se, desta forma, que a metodologia de mapeamento de fragilidade ambiental sugerida por Ross (1994), quando aplicada à especificidade local da BHC$\mathrm{FR}$, restringe o uso dos recursos naturais na medida em que concentra a área da bacia hidrográfica dentro do intervalo das classes de fragilidade potencial alta e muito alta; contudo, sempre que essa metodologia começou a sofrer as alterações apresentadas no decorrer das três cartas restantes, ocorreu distribuição das áreas da BHCFR, em todas as classes, o que torna possível pensar o uso dos recursos naturais em termos de exploração agrícola.

É oportuno fazer uma ressalva com relação à classe baixa fragilidade potencial nas Cartas CFP3 e CFP4; 
FIGURA 5 - COMPARAÇÃO DAS CLASSES DE FRAGILIDADE POTENCIAL (CFP) DE ACORDO COM SUAS RESPECTIVAS CARTAS

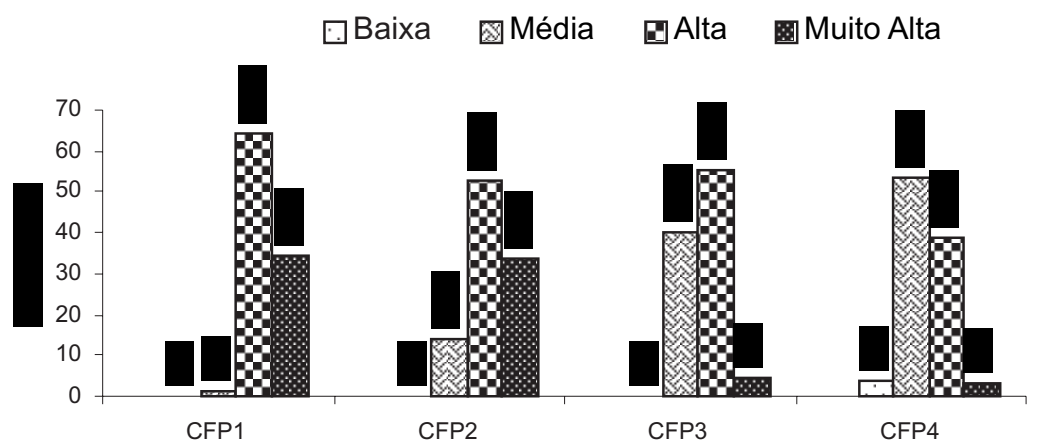

FIGURA 6 - MAPA DE SOLOS DA BHC-FR (EMATER, 1997)

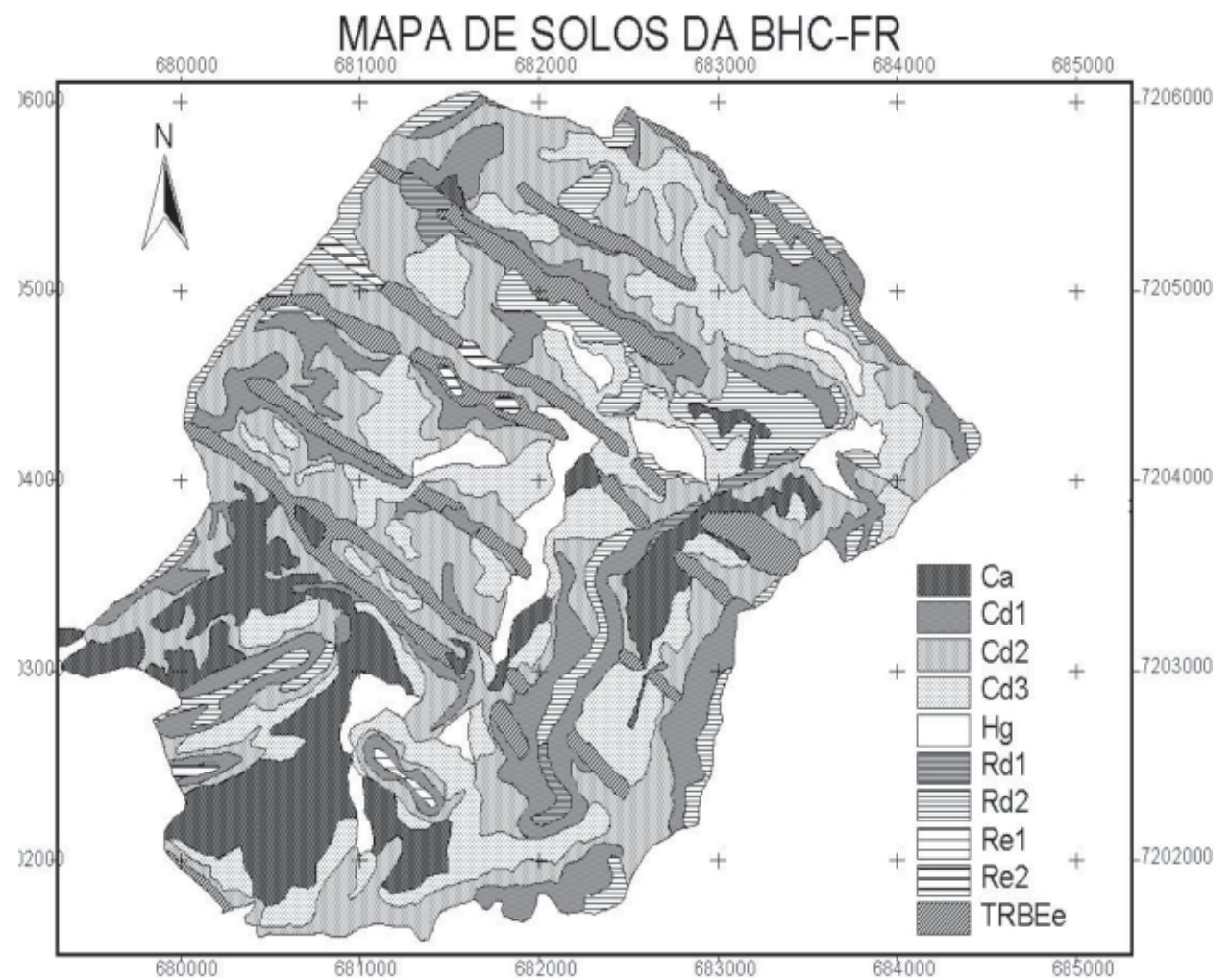

nelas, tal classe é constituída, na sua quase totalidade, pelas seguintes categorias pedológicas: Cambissolos latossólicos, Cambissolos distróficos profundos e Terras Brunas Roxas Estruturadas, cujas distribuições espaciais podem ser vistas na Figura 6.

Em relação aos Cambissolos, a classe de fragilidade potencial baixa parece estar em concordância com suas qualidades, referidas anteriormente em base na literatura.

Por outro lado, e se analisando a Carta de Fragilidade Potencial 1, nota-se uma inversão de valores na conceituação dos Cambissolos latossólicos quanto às suas fragilidades ou potencialidades: na CFP1, os Cambissolos são enquadrados nas classes de alta e muito alta fragilidade potencial, enquanto na CFP4, nas classes de baixa e média fragilidade potencial.

Por vezes, este fato mostra, em parte, a deficiência de qualquer classificação taxonômica ao tentar enquadrar um grupo determinado de elementos dentro de uma única classe, desconsiderando-se, muitas vezes, as especificidades (diferenças) entre cada elemento. No caso dos Cambissolos, eles constituem uma grande clas- 
se que abrange tipo de solos com características semeIhantes, embora entre eles existam diferenças marcantes que refletem na constituição de suas qualidades (fertilidade, resistência à erosão, mecanização, resiliência etc).

Neste trabalho, as metodologias refletem conceitos diferenciados de qualidade (principalmente quanto à erodibilidade) de solo. Na metodologia alternativa proposta, ao contrário da original, considerou-se o Cambissolo Latossólico Húmico (Ca) como o de melhor qualidade, em relação ao total dos solos levantados naquela região, embora fosse apontada, pela Emater (1997), uma boa aptidão agrícola para o Cambissolo Distrófico profundo (Cd3).

Após a discussão dos resultados apresentados na elaboração das quatro cartas de fragilidade potencial, dar-se-á seqüência à análise do uso atual das terras da bacia hidrográfica de Fervida e Ribeirão das Onças, Município de Colombo, Estado do Paraná.

\section{CARTAS DE FRAGILIDADE EMERGENTE DO AMBIEN- TE ANTROPIZADO}

Neste item estarão sendo confrontadas as cartas de fragilidade potencial com o uso atual das terras da bacia hidrográfica de Fervida e Ribeirão das Onças, o que caracterizará, sem dúvida, a vulnerabilidade da área aos tipos exploração agrícola e à ocupação urbana.

Pesos iguais são usados no cruzamento das cartas de fragilidade potencial com a Carta do Uso Atual das Terras (CUAT) da BHC-FR, ou seja, as cartas de fragilidade potencial têm o mesmo peso que a carta de uso das terras, o que influenciará grandemente a fragilidade ambiental ou emergente da área. Não obstante, para a melhor compreensão das Cartas de Fragilidade Emergente (CFE), devem ser relembradas as porcentagens das categorias de uso da BHC-FR. A categoria Agricultu- ra ocupa a maior porção da área bacia hidrográfica $(40,29 \%)$, seguida da categoria Vegetação Natural (VegNat), com 28,21\%, e Vegetação Plantada (Veg-Pla), com 24,35\%; outra informação importante para a abordagem da fragilidade emergente é o conhecimento do tipo de exploração a que estão sendo submetidos os recursos naturais; para tanto, foram cruzados os planos de informação do uso das terras com cada elemento do geossistema (pedologia, declividade, geomorfologia e geologia).

No caso da categoria pedologia, verificam-se, na Figura 7, as tipologias de uso realizadas sobre os solos da área e, no gráfico, constata-se que na tipologia Agricultura são explorados, em maior proporção, os Cambissolos $\mathrm{Ca}$, Cd3 e Cd2 - solos de maior aptidão agrícola segundo Emater (1996) e Hidromórficos, ou seja, nas áreas de várzea.

Ao se confrontar aos usos das terras praticados sobre os diferentes tipos de relevos presentes na área, nota-se que a categoria Agricultura é predominantemente praticada em declividades do tipo plano $(P)$ e suave ondulado (SO); ao passo que nos terrenos mais declivosos predominam outros tipos de usos: Veg_Nate Veg_Plat (Bracatinga) predominam em relevos do tipo montanhoso (M), conforme a Figura 8.

O padrão de uso dos recursos naturais também incide sobre a geologia e pode ser expresso conforme a Figura 9, na qual se nota que a agricultura está assentada em praticamente todas as litologias; contudo, atinge sua maior expressão nos metadolomitos e nos aluviões. As áreas preservadas de vegetação natural localizam-se também sobre todas as geologias, atingindo maior percentual nos diabásios, seguido pelos quartzitos, pelitos, dolomitos e, finalmente, pelos aluviões.

Através dos dados obtidos na construção das cartas de fragilidade emergente pôde-se construir outro gráfico (Figura 10) sintetizando a evolução das classes de

FIGURA 7 - CONFRONTO DOS SOLOS COM AS TIPOLOGIAS DE USO DAS TERRAS DA BHC/FR.

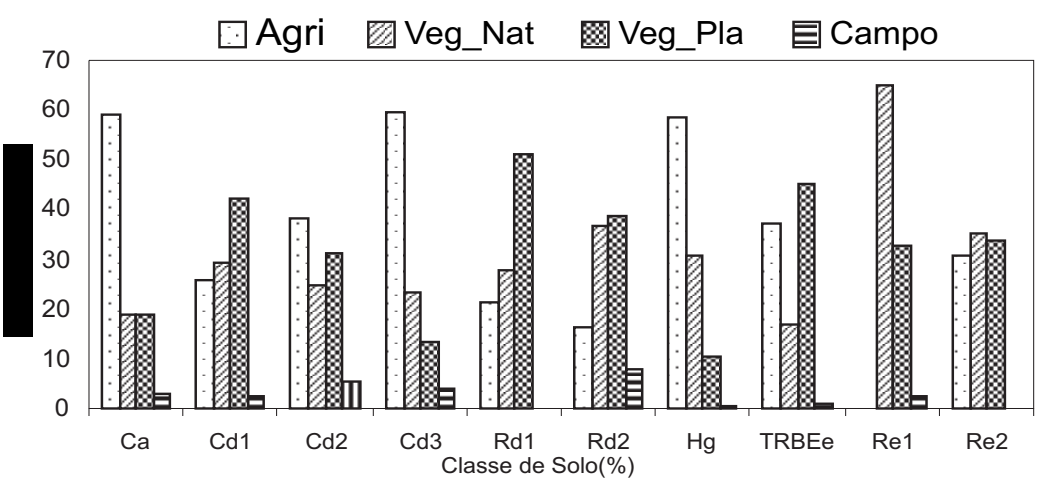



FIGURA 8 - CONFRONTO DAS DECLIVIDADES COM AS TIPOLOGIAS DE USO DAS TERRAS
DA BHC-FR

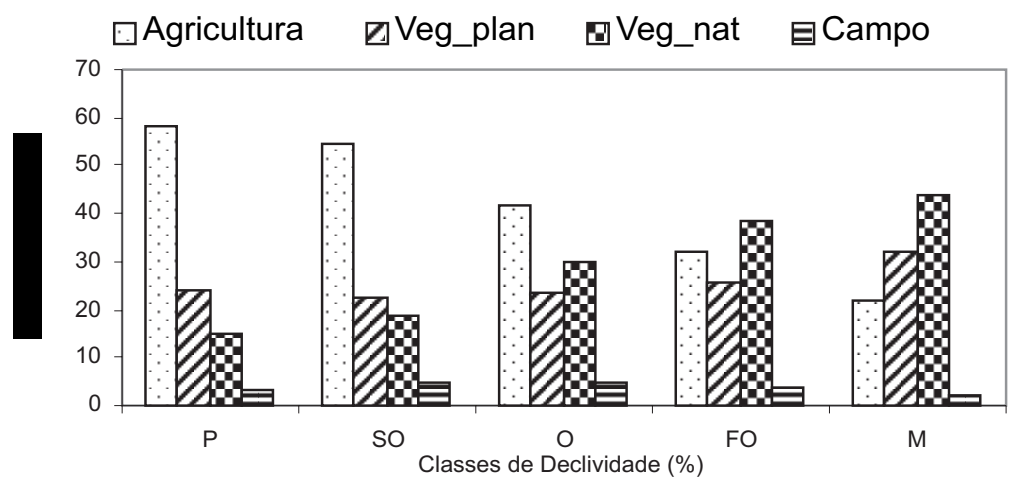

FIGURA 9 -CONFRONTO DAS LITOLOGIAS COM AS TIPOLOGIAS DE USO DAS TERRAS DA BHC-FR.

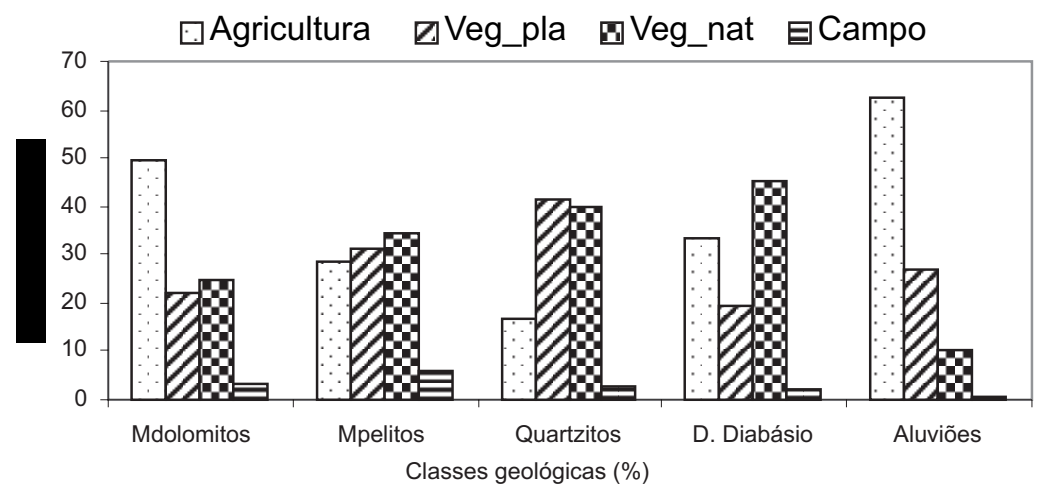

FIGURA 10 - COMPARAÇÃO DAS CLASSES DE FRAGILIDADE EMERGENTE DE ACORDO SUAS RESPECTIVAS CARTAS (CFE)

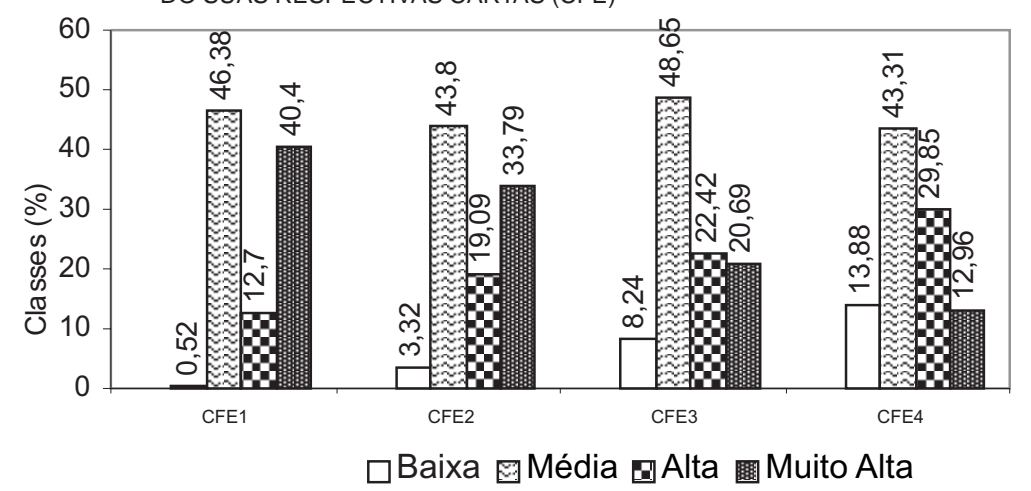

fragilidade potencial frente aos quatro cenários (cartas) construídos no desenvolvimento metodológico.

Notou-se, nesta seqüência, que a classe de fragilidade baixa foi a que recebeu maior aumento contínuo na sua distribuição, partindo de $0,52 \%$ da área da bacia para 13,88\%. Concomitantemente, pode-se notar também um decréscimo da área da classe de muito alta fragilidade do geossistema, frente às atividades agrícolas desenvolvidas, partindo-se de um percentual de 40,4\% da área da bacia para 12,96\%.

O importante a destacar, após a exposição dos resultados, é que a metodologia alternativa proposta neste trabalho partiu do pressuposto de que o geossistema da BHC-FR possui especificidades locais que imprimem ao 
sistema dinâmicas geoecológicas complexas que não são consideradas quando aplicada a metodologia de mapeamento da fragilidade ambiental de forma pura e simples.

Dessa maneira, a escolha por uma ou outra carta de fragilidade potencial só fará sentido, realmente, quando confrontada com o tipo de uso a que está sendo submetido o meio natural, ou seja, dizer que uma área tem maior ou menor fragilidade potencial (leia-se instabilidade morfopedogenética) passa a adquirir outra magnitude (isto é, determinada vulnerabilidade) quando analisado em conjunto com os usos efetivamente praticados no local.

Ora, nem sempre uma intervenção humana no meio é sinônimo de degradação ambiental, desde que a tecnologia empregada seja adequada ao potencial ecossistêmico existente. Para tanto, deve-se conhecer, também, os limites e as potencialidades dos agroecossistemas praticados localmente.

\section{REFERÊNCIAS}

BERTRAND, G. Paisagem e geografia física global: esboço metodológico. Caderno de Ciências da Terra, São Paulo, n. 13, p. 1-27, 1971.

CASSETI, V. Ambiente e apropriação do relevo. São Paulo: Contexto, 1991. p. 147.

Elementos de geomorfologia. Goiânia: Editora de UFG, 2001. p. 137.

CHORLEY, R. J. A geomorfologia e a teoria dos sistemas gerais. Notícia Geomorfológica, Campinas, v. 11, n. 21, p. 322, 1971.

CHRISTOFOLETTI, A. Geomorfologia. São Paulo: Edgard Blucher, Editora da USP, 1974. p. 141.

COMEC. Coordenação da Região Metropolitana de Curitiba (Curitiba, PR). Mapa planialtimétrico folha SG-22-X-D-I 4NO-B. Curitiba, 1976. 1 mapa; $58 \times 85 \mathrm{~cm}$. Escala 1: 10.000 .

EMBRAPA. Centro Nacional de Pesquisa de solos (Rio de Janeiro, RJ). Levantamento de reconhecimento de solos do Estado do Paraná. Londrina, 1984. 2 tomos. (Embrapa-Snlcs. Boletim de Pesquisa, 27: IAPAR. Boletim Técnico, 16).

EMBRAPA. Centro Nacional de Pesquisa de solos (Rio de Janeiro, RJ). Sistema Brasileiro de Classificação de Solos. Brasília: Embrapa Produção de Informação; Rio de Janeiro: Embrapa Solos, 1999. 412 p.

EMATER-Paraná. Mapa de solos da região do Karst. Curitiba,1997. 1 mapa: preto e branco; 59 × $102 \mathrm{~cm}$. Escala: 1:10.000.

Estudo do quadro natural: Karst. Curitiba, 1997. 34 p.

\section{CONCLUSÕES}

1. A escolha de uma ou outra carta dependerá da finalidade que se deseja dar ao uso das terras. Se a finalidade for estritamente a preservação dos recursos naturais (mais especificamente da qualidade da água), a adoção da primeira carta (CFP1) se adequará perfeitamente àquela finalidade.

2. A metodologia de mapeamento da fragilidade ambiental mostra-se adequada para a análise da dinâmica dos geossistemas quando incorpora, junto aos componentes do sistema natural (pedologia, geologia, geomorfologia e vegetação), o fator antrópico, representado pela lógica produtiva e pelo uso dos componentes naturais.

3. O resultado obtido através da metodologia de Ross (1994) poderia induzir aparentemente a um impedimento da utilização efetiva do espaço para fins produtivos.

FIORI, A. P. Evolução geológica da Bacia Açungui. Boletim Paranaense de Geociências, Curitiba, n. 42, p. 7-27, 1994.

FOSTER, S. S. D.; HIRATA, R. C.; ROCHA, G. A. riscos de poluição de águas subterrâneas: uma proposta metodológica de avaliação regional. In: CONGRESSO BRASILEIRO DE ÁGUAS SUBTERRÂNEAS, 5, São Paulo, 1988. Anais... São Paulo: ABAS, p. 175-185.

FRITZSONS, E. Avaliação do impacto da contaminação por nitrogênio na Bacia Hidrográfica Cárstica de Fervida/ Ribeirão das Onças - Colombo/PR. Curitiba, 1999. 164 f. Dissertação (Mestrado em Ciências Florestais) - Setor de Ciências Agrárias, Universidade Federal do Paraná.

FULLER, R.; CARLSSON, C. Fuzzy multiple criteria decision making: recent developments. Fuzzy Sets and Systems, v. 78, 1996, p. 139-153. Disponível em: <www.abo.fi/ rfuller/ fs13.pdf> Acesso em: 17 fev. 2003.

FUNTOWICZ, S. O.; ALIER, J. M.; MUNDA, G.; RAVET, J. R. Information tools for environmental policy under conditions of complexity. Environmental issues series, Luxembourg, $\mathrm{n}$. 9, 1999. Disponível em: <www.eea.eu.int> Acesso em: 03 dez. 2002.

GERRARD, J. Soil Geomorphology: an integration of pedology and geomorphology. London: Chapman \& Hall, 1992.

GOLDBLATT, T. D. Teoria Social e Ambiente. Lisboa: Instituto Piaget, 1998.

HARDY, T. L. Multi-Objective Decision-Making Under Uncertainty: Fuzzy Logic Methods. Cleveland: Nasa, Lewis Research Center. 1995, 16 p. Disponível em: <http:// 
ntrs.nasa.gov/archive/nasa/casi.ntrs.nasa.gov/ 19950010854_1995110854.pdf> Acesso em: 17 fev. 2003.

IGUE, K. Dinâmica da matéria orgânica e seus efeitos nas propriedades do solo. In: SEMINÁRIO ADUBAÇÃO VERDE. 1983, Rio de janeiro. p. 232-267.

INPE. Instituto Nacional de Pesquisas Espaciais. SPRING versão 3.6.3 (plataforma pc Windows). São José dos Campos, 2003.

KIEHL, E. J. Fertilizantes orgânicos. Piracicaba: Editora Agronômica "Ceres", 1985. 492 p.

LISBOA, A. A. Proposta de metodologia para avaliação hidrogeológica do aqüífero cárstico, compartimento de São Miguel. In: SEMINÁRIO DO CURSO DE PÓS-GRADUAÇÃO EM GEOLOGIA. Boletim de resumos... Curitiba, p. 18-20, 1997.

MEDEIROS, G. B. Características, uso e manejo das principais classes de solo. In: PARANÁ. Secretaria da Agricultura e do Abastecimento. Manual técnico do subprograma de manejo e conservação do solo. 2. ed. Curitiba: IAPAR, 1994. p. $51-60$.

MINEROPAR. Mapa Geológico: FolhaA 103 - Área III. Curitiba: Mineropar, 1997. 1 mapa: color; 60 × 80 cm. Escala 1: 20.000 . Convênio: Comec e Mineropar.

OLIVEIRA, J. B.; JACOMINE, P. K. T.; CAMARGO, M. N. Clas- ses gerais de solos do Brasil: guia auxiliar para seu reconhecimento. 2. ed. Jaboticabal: Funep, 1992.

PENTEADO, M. M. Fundamentos de geomorfologia. Rio de Janeiro: IBGE, 1974.

PRIMAVESI, A. O manejo ecológico do solo: agricultura em regiões tropicais. 3. ed. São Paulo: Nobel, 1983.

ROBERT, M. Le sol: interface dans Lénvironnement. Ressource pour le développement. Paris: Manson, 1996. $244 \mathrm{p}$.

ROSS, J. L. S. Análise empírica dos ambientes naturais e antropizados. Revista do Departamento de Geografia FFLCH-USP, São Paulo, n. 8, p. 63-74, 1994.

RUELLAN, A.; DOSSO, M. Regards sur le sol. Paris: Éditions Foucher, 1993.

SOTCHAVA, V. B. Por uma teoria de classificação de geossistemas de vida terrestre. Biogeografia, São Paulo, n. 14, 1978. p. 1-24.

TEODOROVICZ, A; TEODOROVICZ, A. M. G.; CANTARINO, S. C. Projeto Curitiba. Informações básicas sobre o meio físico: subsídios para o planejamento territorial. Folha Curitiba - 1:100.000. Curitiba: CPRM, Coordenação da Região Metropolitana de Curitiba, 1994. 109 p.

TRICART, J. Ecodinâmica. Rio de Janeiro: IBGE, 1977. p. 91. 